MATEC Web of Conferences 13, 03013 (2014)

DOI: $10.1051 /$ matecconf/ 20141303013

(C) Owned by the authors, published by EDP Sciences, 2014

\title{
Experimental Prediction of Wear Rate on Rail and Wheel Materials at Dry Sliding Contact
}

\author{
Windarta and M. B. Baharom \\ Mechanical Engineering Department, Universiti Teknologi PETRONAS, Bandar Seri Iskandar, Perak \\ 31750, Malaysia
}

\begin{abstract}
This research is aimed at predicting the rail gauge and wheel flange contacts and their influences to wear rate using pin-on-disc method. A real model using a pin to represent a wheel component and a disc to represent a rail component were fabricated for the experiments. The experimental results were analyzed and the empirical formula of the wear depths as functions of applied load, bulk temperature and sliding velocity were obtained to describe the behavior of the systems. The results showed that the wear depth increased linearly with the increasing in applied load and temperature, while it decayed exponentially with the sliding velocity. The results were found to agree with the twin disc models from previous research works.
\end{abstract}

\section{Introduction}

Rail and wheel suffer damage on each contact surfaces such as wear, erosion and plastic deformation. The wear of material is based on the operating condition of surfaces where a slight change may influence the wear rate significantly. For the case of the railway operation, cyclic loading exists on both wheel and rail. The wheel load which consists of contact stress distribution, subsurface stress, and plastic deformation can lead to rolling contact fatigue.

The lubrication system of rail and wheel contact surfaces to decrease the wear rate is currently available; however wear is still a huge problem on rail and wheel contact due to abnormal operating conditions. The maintenance cost of wear and fatigue of wheel and rail contacts is estimated to be about 1.2 billion USD in China annually [1]. The wear of rail gauge and wheel flange contact has been found to be more severe as compared to the rail head and wheel tread contact [2]. The surface interaction of the rail gauge and wheel flange can be considered as sliding contact.

Over the years, a number of wear theories that are applicable to the rail vehicle wheels and rails have been formulated [3]-[12]. These theories apply to wear processes in various wear regimes, and they range in complexity from a single parameter to relatively complex expressions. At the same time, the understanding of the contact patch mechanics and of rail vehicle dynamic modeling has been developed using analytical predictions of the forces and motions in the contact patch with fair confidence.

Many researchers have proposed rail head and wheel tread contact models. Two roller rigs have been chosen to simulate rail head and wheel tread contact [4]-[6]. It was found that the rolling-sliding contact occurs in the surface contacts. Four wear modes, referred to as mild, severe, heavy and catastrophic, have been identified in the laboratory tests[3], [6]-[10]. 
A few researchers have proposed a model of sliding contact interaction between rail and wheel [11], [12]. Lee and Polycarpou [11] simulated sliding contact using scratch apparatus test. This method allowed many scratches at the same location. Asih et al. [12] simulated sliding contact using finite elements method. Based on these results, many researchers have decided to use the rail head and wheel tread contacts for their analysis, but only few researchers used the model of sliding contact of rail gauge and wheel flange.

This paper aims to determine the wear rate using pin-on-disc method. Research on the wear of rail and wheel contact has investigated in single factor, such as contact pressure, sliding velocity, and temperature contact. The interaction effect of combining factors on the rail and wheel wear has lack in consideration. This work is focused upon wheel flange-rail gauge wear analysis on combining factor effect. Wheel flange-rail gauge contact could be simulated using pin-on-disc method. Pin-on-disc laboratory simulations were used for prediction of actual rail and wheel sliding wear at dry condition.

\section{Method and materials}

\subsection{Materials and experimental setup}

The compositions of materials used in this research are shown in Table 1, namely UIC 60 rail steel and R8 wheel. The experiments were conducted using Ducom multi specimen testing machine designed according to ASTM G99 standards [13]. The rail steel was cut to form disk specimens, with each having dimensions of $42 \mathrm{~mm}$ in diameter and $5 \mathrm{~mm}$ in thickness. The pin samples were prepared to have dimension of $6 \mathrm{~mm}$ in diameter and $12 \mathrm{~mm}$ in length.

Table 1. Composition of rail and wheel materials.

\begin{tabular}{lllllll}
\hline & $\mathrm{C}$ & $\mathrm{Mnn}$ & $\mathrm{P}$ & $\mathrm{S}$ & $\mathrm{Si}$ & $\mathrm{Fe}$ \\
\hline Rail & 0.71 & 0.87 & 0.02 & 0.01 & 0.29 & Balance \\
Wheel & 0.53 & 0.69 & 0.02 & 0.01 & 0.28 & Balance \\
\hline
\end{tabular}

\subsection{Wear rate experiments}

Both pin and disc samples were fabricated using the real rail and wheel materials. The calculations of wear rate was done for pin and disc materials in dry conditions. The testing was performed under pin rotating speed of 100, 200, 300, 400, 1000, and $2000 \mathrm{rpm}$. Each specimen was tested under 40, 60, 80, 100 and $120 \mathrm{~N}$ loads. The schematic diagram of the experiment is shown in figure 1.

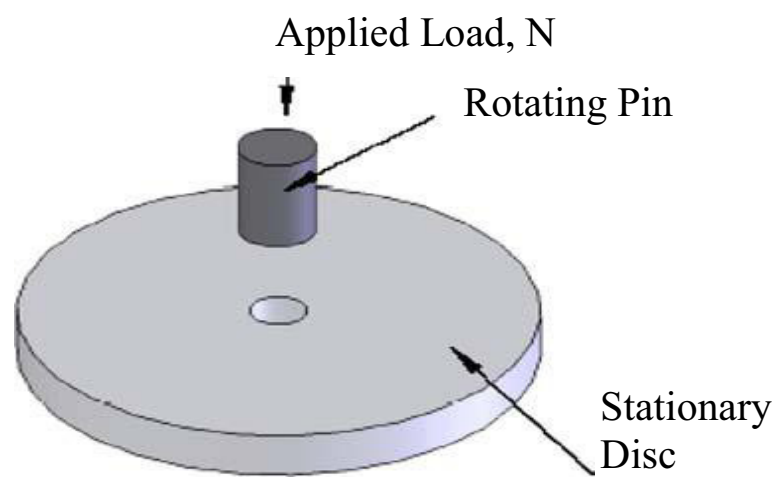

Fig. 1. Schematic diagram of Pin-on-disc experiment 


\section{Results and discussion}

Fig. 2. shows the raw results obtained from the wear test machine. For the steady state condition, the depths of wears are $88.63 \mu \mathrm{m}, 125.66 \mu \mathrm{m}, 263.01 \mu \mathrm{m}, 395.67 \mu \mathrm{m}$ and $451.37 \mu \mathrm{m}$ for applied loads of $40,60,80,100$ and $120 \mathrm{~N}$ respectively. In general, the depth of wear increases linearly with increasing applied contact loads. The relationship between the applied load and wear depth is:

$$
\text { Wear depth }=4.6369 .(\text { applied load })-112.1376
$$

These results have the same trend compared to the studies conducted by Lewis \& Olofsson who used twin discs model [14].

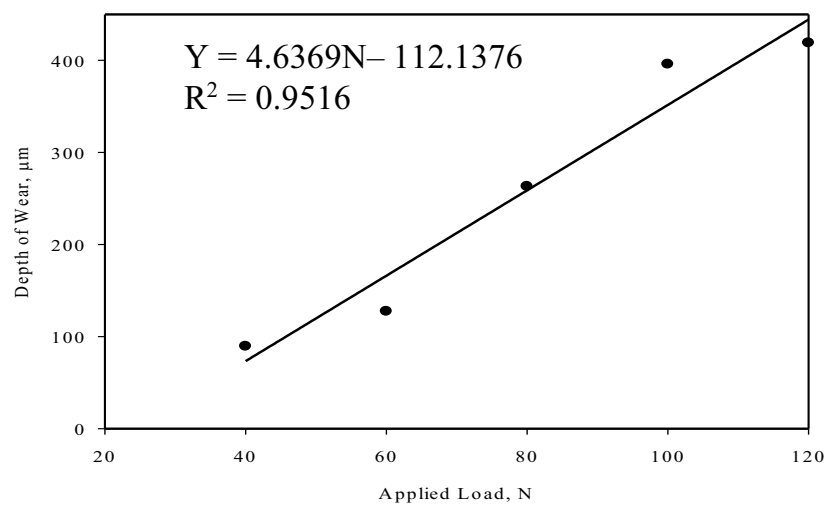

Figure 2. Depth of wear vs. applied load

The change of depth of wear due to velocity variation is presented in Fig. 3. The depths of wear due to the velocity variations are found to be $395.67,465.72,604.66,722.15,843.97$ and $918.16 \mu \mathrm{m}$ for velocities of $0.15,0.31,0.47,0.63,1.57$ and $3.14 \mathrm{~m} / \mathrm{s}$ respectively. The wear rate of materials increases with exponential decay with the increase in velocity at a constant load. This finding has similar trend as the results obtained by Telliskivi \& Olofsson[6] who also used twin disc methods. The relationship between the sliding velocity and wear depth is:

$$
\text { Wear depth }=882.4029(1-\exp (-2.4430(\text { sliding velocity })))
$$

From equation 2, it can be predicted that the wear rate approaches to the value of $882 \mu \mathrm{m}$ as the velocity increases to infinity.

The depth of wear is influenced by various bulk temperatures are shown in Fig. 4. The wear depths are found to be $395.67 \mu \mathrm{m}, 768.45 \mu \mathrm{m}, 1184.78 \mu \mathrm{m}$, and $1447.86 \mu \mathrm{m}$ for the bulk temperatures of 298 , 323,348 , and $378 \mathrm{~K}$ respectively. The relationship between the bulk temperature and wear depth is:

$$
\text { Wear depth }=-3827.0303+14.2692 \text { (bulk temperature) }
$$

These results have the same trend compared to the studies conducted by Gallardo-Hernandez et al. who used twin discs model [15]. 


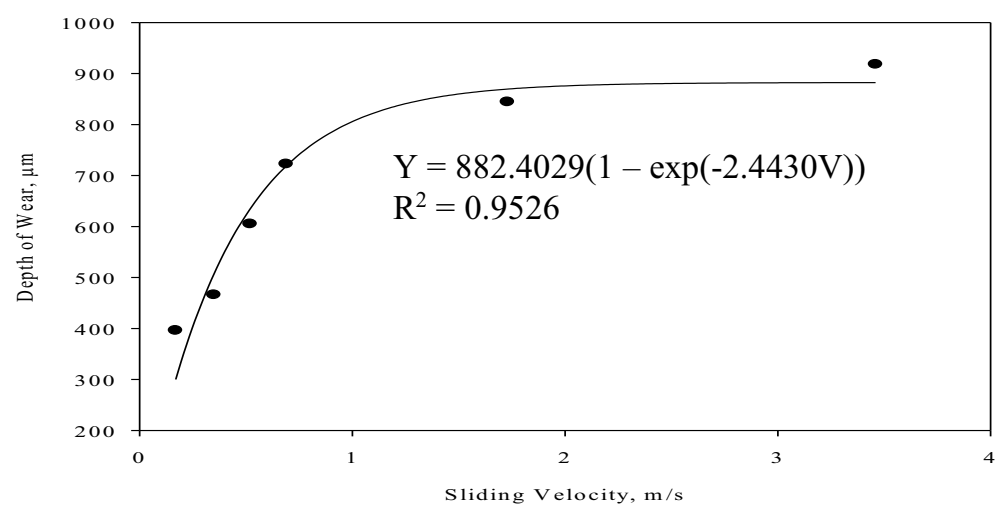

Fig. 3. Depth of wear vs. sliding velocity

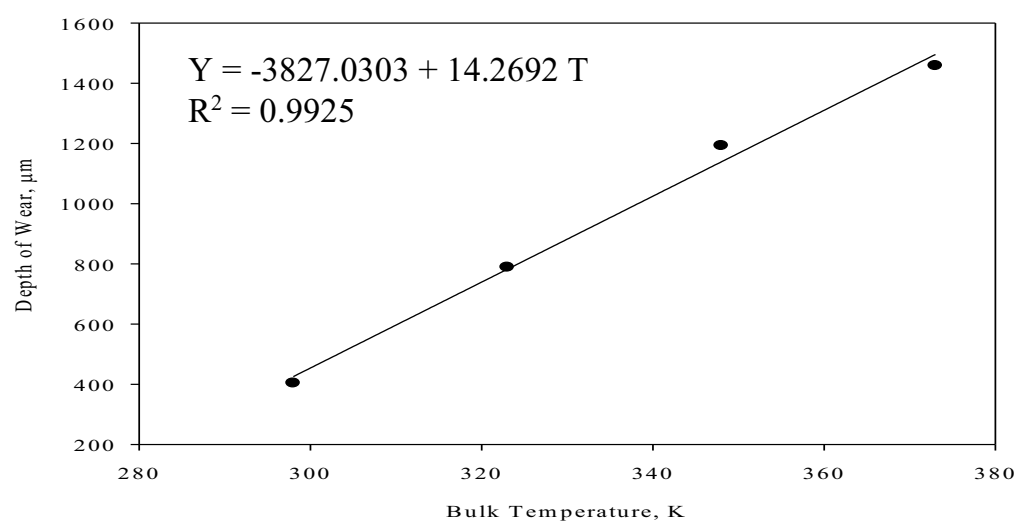

Fig. 4. depth of wear vs. bulk temperature

\section{Conclusions}

In this study, wear characteristics for railway material were investigated using pin-on-disc method. For steady state condition, the depths of wears were found to be $88.63 \mu \mathrm{m}, 125.66 \mu \mathrm{m}, 263.01 \mu \mathrm{m}$, $395.67 \mu \mathrm{m}$ and $451.37 \mu \mathrm{m}$ for applied loads of 40,60,80, 100 and $120 \mathrm{~N}$ respectively. The wear rate values of materials increased linearly with increasing in applied load and bulk temperature. The depths of wear due to velocity variations were found to be $395.67,465.72,604.66,722.15,843.97$ and $918.16 \mu \mathrm{m}$ for pin velocities of $0.15,0.31,0.47,0.63,1.57$ and $3.14 \mathrm{~m} / \mathrm{s}$ respectively. The wear rate of materials increases with the exponential decay with the increase in velocity at a constant load.

All of these results were found to agree with the experimental results obtained from the twin disc models. Finally, it is concluded that the wear characteristics of the rail and wheel can be predicted using pin-on-disc method which is simpler to be used.

\section{Acknowledgment}

The authors would like to thank Keretapi Tanah Melayu Berhad (KTMB) for providing railway and wheel materials. This research is under Universiti Teknologi PETRONAS Graduate Assistantship. 


\section{Nomenclature}

$\begin{aligned} \mathrm{Y} & =\text { The depth of wear, } \mu \mathrm{m} \\ \mathrm{T} & =\text { Bulk temperature, } \mathrm{K} \\ \mathrm{V} & =\text { Sliding velocity, } \mathrm{m} / \mathrm{s} \\ \mathrm{N} & =\quad \text { Normal applied load, } \mathrm{N}\end{aligned}$

\section{References}

[1] X. Jin, Z. Wen, X. Xiao, and Z. R. Zhou, Multibody Syst. Dyn., 18, 4, 531-557, (2007)

[2] S. Descartes, a. Saulot, C. Godeau, S. Bondeux, C. Dayot, and Y. Berthier, Wear, 271, 1-2, 54-61, (2011)

[3] S. Zakharov, I. Komarovsky, and I. Zharov, Wear, 215, 1-2, 18-24, (1998)

[4] A. Matsumoto, Y. Sato, M. Nakata, M. Tanimoto, and K. Qi, Wear, 191, 1-2, 101-106, (1996)

[5] A. Matsumoto, Y. Sato, H. Ono, M. Tanimoto, Y. Oka, and E. Miyauchi, Wear, 253, 1-2, 178-184, (2002)

[6] T. Telliskivi and U. Olofsson, Wear, 257, 11, 1145-1153, (2004)

[7] K. D. Van and M. H. Maitournam, Wear, 253, 1-2, 219-227, (2002)

[8] R. Enblom and M. Berg, Wear, 258, 7-8, 1055-1063, (2005)

[9] F. Bucher, A. I. Dmitriev, M. Ertz, K. Knothe, V. L. Popov, S. G. Psakhie, and E. V. Shilko, Wear, 261, . 7-8, 874-884, (2006)

[10] A. Matsumoto, Y. Sato, H. Ohno, M. Tomeoka, K. Matsumoto, J. Kurihara, T. Ogino, M. Tanimoto, Y. Kishimoto, and T. Nakai, Wear, 265, 9-10, 1518-1525, (2008)

[11] K. M. Lee and A. A. Polycarpou, Wear, 271, 7-8, 1174-1180, (2011)

[12] A. M. S. Asih, K. Ding, and A. Kapoor, Tribol. Lett., 49, 239-249, (2013)

[13] ASTM G99-05, Ed., Standard Test Method for Wear Testing with a Pin-on-Disc Apparatus. West Conshohocken, PA: ASTM International, (2010)

[14] R. Lewis and U. Olofsson, 6th International Conference on Contact Mechanics and Wear of Rail/Wheel Systems (CM2003), (2003)

[15] E. A. Gallardo-Hernandez, R. Lewis, and R. S. Dwyer-Joyce, Tribol. Int., 39, 12, 1653-1663, (2006)

[16] U. Olofsson and T. Telliskivi, Wear, 254, 1-2, 80-93, (2003) 